\title{
The cytotoxin of Actinobacillus pleuropneumoniae (pleurotoxin) is distinct from the haemolysin and is associated with a $120 \mathrm{kDa}$ polypeptide
}

\author{
Andrew N. Rycroft, ${ }^{*}$ Duncan Williams, Janice M. Cullen and Julie Macdonald \\ Department of Veterinary Pathology, University of Glasgow, Glasgow G61 1QH, UK
}

(Received 29 August 1990; revised 21 November 1990; accepted 29 November 1990)

\begin{abstract}
Mutants of Actinobacillus pleuropneumoniae strain HK 361 (serotype 2) were isolated which were deficient in type II $\left(\mathrm{Ca}^{2+}\right.$-dependent) haemolysin activity $\left(\mathrm{Hly}^{-}\right)$. Some of the $\mathrm{Hly}^{-}$mutants secreted a potent, heat-labile extracellular cytotoxic activity against porcine alveolar macrophages. Comparison of cell-free culture supernatant from the parent strain and some $\mathrm{Hly}^{-}$mutants by SDS-PAGE and immunoblotting revealed the loss of a major extracellular polypeptide of $109 \mathrm{kDa}$. Two $\mathrm{Hly}^{-}$mutants which in addition failed to secrete a $120 \mathrm{kDa}$ polypeptide produced no extracellular cytotoxic activity, suggesting that the $120 \mathrm{kDa}$ protein was the cytotoxin. Antiserum raised to the culture supernatant from a $\mathrm{Hly}^{-}$mutant lacking the $109 \mathrm{kDa}$ polypeptide recognized the $120 \mathrm{kDa}$ band, but not the $109 \mathrm{kDa}$ band, in immunoblots and neutralized the cytotoxic activity, but not the haemolytic activity, of $A$. pleuropneumoniae. The $120 \mathrm{kDa}$ polypeptide and extracellular cytotoxic activity were widespread among $A$. pleuropneumoniae strains, but absent from related bacterial pathogens of the pig: Actinobacillus suis, Haemophilus parasuis and Pasteurella multocida. A clear correlation was found between the presence of the $120 \mathrm{kDa}$ polypeptide and cytotoxic activity in culture supernatants. The cytotoxic activity of all the strains tested was neutralized by antibody to the $\mathrm{Hly}^{-}$extracellular material and by convalescent pig serum. It is proposed that the $120 \mathrm{kDa}$ polypeptide represents the cytotoxin of $A$. pleuropneumoniae, that it is distinct from the haemolysin, and that it be termed pleurotoxin.
\end{abstract}

\section{Introduction}

Actinobacillus pleuropneumoniae is the aetiological agent of contagious porcine pleuropneumonia (Nicolet, 1986; Sebunya \& Saunders, 1983). Evidence for the involvement of one or more toxins in the disease includes the rapid course of acute pleuropneumonia (Shope, 1964; Bertram, 1988), the vascular changes associated with the lesions (Liggett et al., 1987) and the finding that cell-free culture supernatant material can induce lung lesions similar to those of natural infection (Rosendal et al., 1980). The organism is known to secrete both haemolytic and cytotoxic activities which may contribute to the development of lesions, but it is not clear whether these activities are properties of the same protein or are distinct.

Cytotoxic activity of $A$. pleuropneumoniae was first demonstrated in vitro by Bendixen et al. (1981). Both heat-labile and heat-stable activities were found. Since then, a number of observations of cytotoxic activity have

Abbreviation: PAM, porcine alveolar macrophages. been reported (Kume et al., 1986; Rosendal et al., 1988; Van Leengoed et al., 1989).

The haemolysin has been the subject of a number of studies which have led to the suggestion that it is a major virulence factor in porcine pleuropneumonia (Martin et al., 1985; Rosendal et al., 1988). The haemolysin of serotype 1 was identified as a protein of approximately 104 kDa (Devenish \& Rosendal, 1989; Frey \& Nicolet, $1988 a$ ). More recently, the gene encoding the haemolysin of serotype 1 has been cloned (Chang et al., 1989; Gygi et al., 1990) and shown to be related to the group of extracellular toxin proteins, including the leucotoxin of Pasteurella haemolytica, and the HlyA of Escherichia coli (Chang et al., 1987; Strathdee \& Lo, 1987). Haemolysins from different serotypes of $A$. pleuropneumoniae differ in their requirements for $\mathrm{Ca}^{2+}$ for production, or for activity upon erythrocytes (Frey $\&$ Nicolet, $1988 b$ ). The activity produced only when $\mathrm{Ca}^{2+}$ was present during growth was termed type I haemolysin, while the haemolysin requiring $\mathrm{Ca}^{2+}$ for its lytic action (resembling the HlyA activity of Escherichia coli; Ludwig et al., 1988; Rennie et al., 1974) was termed type II. However, the haemolysin proteins of all 12 serotypes have since 
been shown to be immunologically cross-reactive and of identical size (Devenish et al., 1989), suggesting that they are closely related molecules despite differences in activity.

It was reported by Udeze \& Kadis (1988) that the haemolysin of the serotype 1 type strain of $A$. pleuropneumoniae, purified by gel filtration and ion-exchange chromatography, was cytotoxic for a variety of pig leucocytes including alveolar macrophages. The haemolysin was considered to be the primary candidate for the toxic activity against lung macrophages and polymorphonuclear leucocytes (Nicolet, 1990; Chang et al., 1989; Devenish \& Rosendal, 1989; Kamp \& Van Leengoed, 1989; Udeze et al., 1987). However, some observations suggested that the haemolytic and cytotoxic activities of A. pleuropneumoniae varied independently (Kamp \& Van Leengoed, 1989; Rosendal et al., 1988) and displayed different properties such as heat stability (Fedorka-Cray et al., 1990). One explanation for this was differences in the biochemical structure of the haemolysin/cytotoxin molecule between strains (Devenish et al., 1989). In the present study we show that cytotoxic activity in a serotype 2 strain is independent of haemolytic activity and identify the polypeptide associated with the cytotoxic activity.

\section{Methods}

Bacteria and culture conditions. The bacterial strains used are listed in Table 2. Actinobacillus pleuropneumoniae strains were stored in $10 \%$ $(w / v)$ skimmed milk at $-70^{\circ} \mathrm{C}$. Routine culture was made on heated blood agar (prepared with $7 \%, \mathrm{v} / \mathrm{v}$, horse blood) and liquid cultures were grown in Tryptone Soya Broth (Oxoid) supplemented with $2 \mu \mathrm{g}$ NAD ml ${ }^{-1}$ (TSB/NAD). Actinobacillus suis, Pasteurella multocida and Haemophilus parasuis were stored lyophilized and cultured in the same media. Cultures were grown initially to the exponential phase $(2-3 \mathrm{~h})$. Subcultures were then made ( 1 in 50) to fresh TSB/NAD and grown with gentle aeration to achieve maximum yields of activity $(2 \cdot 3 \mathrm{~h}$ for haemolytic activity, $4.0 \mathrm{~h}$ for extracellular cytotoxic activity). The comparative growth rate of cultures was determined by measuring the $\mathrm{OD}_{550}$ of the culture at intervals during the growth phase.

CAMP factor. Production of CAMP factor cohaemolysin was determined by cross-streaking with a $\beta$-toxigenic strain of Staphylococcus aureus (Frey et al., 1989).

Polyclonal antibodies. Antibody to whole, cell-free culture supernatant was raised in New Zealand White rabbits by intramuscular injection of filtered supernatant (Millex GV, $0.22 \mu \mathrm{m}$, low protein binding; Millipore) with Freund's incomplete adjuvant. This was followed by three biweekly intravenous injections of the same material without adjuvant (Harlow \& Lane, 1988). Animals were bled after a further $7 \mathrm{~d}$. Convalescent pig serum was obtained from a pig recovering from pleuropneumonia in an outbreak with $A$. pleuropneumoniae serotype 3 (strain 6664).

SDS-PAGE and immunoblotting. SDS-PAGE was carried out as previously described (Rycroft \& Taylor, 1987). The separating gel consisted of $10 \%(\mathrm{w} / \mathrm{v})$ acrylamide (acrylamide/bisacrylamide ratio,
$75: 1)$ in $0.37 \mathrm{~m}$-Tris/HCl (pH 8.7), $0.1 \%$ (w/v) SDS. The stacking gel consisted of $5 \%(\mathrm{w} / \mathrm{v})$ acrylamide (acrylamide/bisacrylamide ratio, $36: 1$ ) in $125 \mathrm{~mm}$-Tris/ $\mathrm{HCl}(\mathrm{pH} 6.9), 0.1 \%$ (w/v) SDS. Culture supernatant for analysis was concentrated 20 -fold by precipitation with ethanol $(23 \%, v / v)$ for $2 \mathrm{~h}$ at $0{ }^{\circ} \mathrm{C}$ followed by centrifugation for $5 \mathrm{~min}$ in a microfuge $(11600 \mathrm{~g})$. Supernatant was discarded and pellets were redissolved in $150 \mathrm{~mm}-\mathrm{NaCl}$. Samples were adjusted to $60 \mathrm{~mm}$ Tris $/ \mathrm{HCl}, 10 \%$ (v/v) glycerol, $2 \%$ (w/v) SDS, $5 \%$ (v/v) $\beta$-mercaptoethanol and electrophoresed at $25 \mathrm{~mA}$ in $25 \mathrm{~mm}$-Tris, $192 \mathrm{~mm}$-glycine (pH 8.3). Proteins were visualized by fixing and staining with $0.25 \%$ (w/v) Coomassie blue R in $10 \%(v / v)$ acetic acid, $40 \%(v / v)$ methanol followed by destaining in the same solvent.

For immunoblotting, culture supernatant was used unconcentrated. Gels were washed in $25 \mathrm{~mm}$-Tris, $192 \mathrm{mM}$-glycine for $20 \mathrm{~min}$ at room temperature. Proteins were electrophoretically transferred onto nitrocellulose in a Trans Blot apparatus (Bio-Rad) in $25 \mathrm{~mm}$-Tris, $192 \mathrm{~mm}$ glycine without methanol. Antigens were probed overnight with whole serum diluted (1 in 200) in $10 \mathrm{~mm}$-Tris/ $\mathrm{HCl}, 150 \mathrm{~mm}-\mathrm{NaCl}, 0.05 \%(\mathrm{v} / \mathrm{v})$ Tween 20 (TNT) containing $5 \%$ skimmed milk. Antigens were detected using horseradish peroxidase conjugated second antibody (goat anti-rabbit or rabbit anti-pig, 1:3000) followed by reaction with substrate $\left[0.05 \%(\mathrm{w} / \mathrm{v})\right.$ 4-chloro-1-naphthol, $4.4 \mathrm{mM}-\mathrm{H}_{2} \mathrm{O}_{2}$ in $16 \%(\mathrm{v} / \mathrm{v})$ methanol, $10 \mathrm{~mm}-\mathrm{Tris} / \mathrm{HCl}(\mathrm{pH} 8.0), 150 \mathrm{~mm}-\mathrm{NaCl}$ ].

Mutagenesis and screening. Mutagenesis with $N$-methyl- $N^{\prime}$-nitro- $N$ nitrosoguanidine (NTG) was carried out essentially as described by Miller (1972) except that $100 \mathrm{~mm}$-Tris/maleate buffer (pH 5.8) was used during the period of exposure to NTG. Briefly, exponential-phase bacteria were washed in Tris/maleate buffer and NTG was added to a final concentration of $50 \mu \mathrm{g} \mathrm{ml}^{-1}$. Bacteria were incubated at $37^{\circ} \mathrm{C}$ for $20 \mathrm{~min}$ and diluted in $0.1 \mathrm{M}$-phosphate-buffered saline $(\mathrm{pH} 7 \cdot 2)$. Mutagenized cultures were spread onto double-layer screening plates comprising a lower layer of Nutrient Agar (Oxoid) containing approximately $5 \times 10^{4}$ c.f.u. $\mathrm{ml}^{-1}$ of Staphylococcus epidermidis as feeder strain and an upper layer of $5 \%(\mathrm{v} / \mathrm{v})$ sheep blood agar. Cultures were incubated for $18 \mathrm{~h}$ before examination for haemolysin-deficient colonies.

Haemolysin determination and neutralization. Culture supernatant from parent and mutant strains was cleared by centrifugation $(10000 \mathrm{~g}$ for $10 \mathrm{~min}$ at $4{ }^{\circ} \mathrm{C}$ ) and filtered through a Millex-GV filter. Fifty microlitres of culture supernatant was diluted in $350 \mu \mathrm{I} 50 \mathrm{~mm}$ Tris/ $\mathrm{HCl}, 150 \mathrm{~mm}-\mathrm{NaCl}, 23 \mathrm{~mm}-\mathrm{CaCl}_{2}$ (pH 7.2) in a microcentrifuge tube. Then $400 \mu \mathrm{l}$ of $5 \%(\mathrm{v} / \mathrm{v})$ sheep erythrocytes, washed twice in $150 \mathrm{~mm}-\mathrm{NaCl}$, was added and incubated for $60 \mathrm{~min}$ at $37^{\circ} \mathrm{C}$. Tubes were mixed gently, centrifuged for $15 \mathrm{~s}$ in a microfuge and the $A_{541}$ of the supernatant was measured. Haemolysin concentration showed a linear relationship with $A_{541}$.

The presence of intracellular haemolysin was examined following ultrasonic lysis of bacteria. Bacteria were centrifuged and resuspended in 0.1 volumes of $50 \mathrm{mM}$-Tris $/ \mathrm{HCl}, 150 \mathrm{~mm}-\mathrm{NaCl}$ at $0{ }^{\circ} \mathrm{C}$. Bacteria were disrupted by sonication for $30 \mathrm{~s}$; cell breakage was judged complete by the microscopic appearance of the cell suspension. Insoluble material was pelleted in a microfuge and the supernatant was assayed for haemolytic activity as described above. Whole bacteria were analysed for immunologically cross-reactive material by dissolving approximately $5 \times 10^{8}$ actively growing bacteria in $60 \mathrm{~mm}$ - Tris/ $\mathrm{HCl}(\mathrm{pH} 6.8), 2 \%$ (w/v) SDS, $10 \%(v / v)$ glycerol, $5 \%(v / v) \beta$-mercaptoethanol at $100{ }^{\circ} \mathrm{C}$ for $5 \mathrm{~min}$ (Gulig et al., 1983). Dissolved proteins were analysed by SDSPAGE followed by immunoblotting.

Haemolysin-neutralizing activity of serum was determined by mixing $10 \mu \mathrm{l}$ of test serum or diluted test serum with $90 \mu \mathrm{l}$ of haemolytically active cell-free culture supernatant. Samples were held at $0{ }^{\circ} \mathrm{C}$ for $60 \mathrm{~min}$ and assayed for haemolytic activity alongside controls treated identically with normal pooled or preimmune serum. 
The neutralizing titre was expressed as the reciprocal of the dilution of serum required to achieve at least $50 \%$ reduction in haemolytic activity of a standard fresh haemolysin preparation (that giving an $A_{541}$ of approximately $1 \cdot 3$ ).

Porcine alveolar macrophages (PAM), cytotoxicity determination and neutralization. Alveolar macrophages were obtained by lung lavage of freshly killed 10-16-week-old pigs, clinically and bacteriologically free from respiratory infection. The respiratory tract was removed and approximately $1000 \mathrm{ml}$ of Hanks' Balanced Salts Solution (HBSS; Gibco BRL) was poured into the lungs. A volume of approximately $600 \mathrm{ml}$ was recovered by draining and was centrifuged at $110 \mathrm{~g}$ for $5 \mathrm{~min}$ (Leijh et al., 1986). The recovered cells were resuspended to $10^{6}$ cells $\mathrm{ml}^{-1}$ in Minimal Essential Medium (Gibco BRL) with $15 \%(\mathrm{v} / \mathrm{v})$ newborn calf serum (MEM) and $60 \mu \mathrm{g}$ gentamicin $\mathrm{ml}^{-1}$. Cells were cultured in 24-well culture plates (Nunc), $10^{6}$ cells per well, in an atmosphere of $3 \%(v / v) \mathrm{CO}_{2}$ in air. The medium was changed after $2 \mathrm{~h}$ incubation and the proportion of viable cells, determined by exclusion of Trypan blue dye (see below), was shown to be greater than $99 \%$. PAM were used within $6 \mathrm{~h}$.

Cytotoxic activity was determined by treating freshly prepared PAM in $900 \mu \mathrm{l} \mathrm{MEM}$ with $100 \mu \mathrm{l}$ of diluted, cell-free culture supernatant and incubating at $37^{\circ} \mathrm{C}$ for $60 \mathrm{~min}$. Cells damaged by the cytotoxic activity showed loss of refractility and became detached from the plastic. After incubation the medium was replaced with $0.1 \%$ Trypan blue in MEM. The proportion of cells stained by Trypan blue was determined after $30 \mathrm{~min}$. One unit of cytotoxic activity was defined as that quantity of toxin which induced $50 \%$ of the cells to stain with Trypan blue or become detached, in a volume of $1.0 \mathrm{ml}$, after incubation for $60 \mathrm{~min}$ at $37^{\circ} \mathrm{C}$. Heat lability of toxic activity was determined by preheating for $5 \mathrm{~min}$ before testing. Intracellular cytotoxic activity was examined following ultrasonic lysis of bacteria as described for haemolysin.

Cytotoxic-neutralizing antibody was determined by mixing $50 \mu \mathrm{l}$ of cytotoxin preparation ( 80 units $\mathrm{ml}^{-1}$ ) with an equal volume of serum (or serum diluted in $150 \mathrm{mM}-\mathrm{NaCl}$ ) at $0{ }^{\circ} \mathrm{C}$ for $60 \mathrm{~min}$. The sample was then added to $0.9 \mathrm{ml}$ MEM in a well of PAM as previously described. The neutralization titre was expressed as the reciprocal dilution of serum required to entirely prevent the cytotoxic effect of the test mixture.

\section{Results}

\section{Isolation of haemolysin-deficient $\left(\right.$ Hly $\left.^{-}\right)$mutants of A. pleuropneumoniae HK361}

A. pleuropneumoniae HK 361 (serotype 2) produced type II ( $\mathrm{Ca}^{2+}$-dependent) haemolysin activity and cytotoxic activity against porcine alveolar macrophages (PAM). Analysis of the cell-free culture material by SDS-PAGE revealed several polypeptides, including two dominant bands of 109 and $120 \mathrm{kDa}$ (Fig. 1, lane 2). In order to establish the identity of the haemolytic protein we sought $\mathrm{Hly}^{-}$mutants of this strain. Approximately 40000 potential mutants were screened following NTG mutagenesis. Twenty-seven colonies having no zone of haemolysis on screening plates were purified and tested for extracellular haemolysin activity, growth rate, CAMP factor and extracellular polypeptides by SDSPAGE and immunoblotting.

\section{Expression of extracellular cytotoxin against PAM in Hly- mutants}

Eight of the mutants secreted no detectable haemolytic activity: $2.3 \mathrm{~h}$ culture fluid showed an $A_{541}$ of $<0.01$ in the haemolysin assay compared to the value of 1.3 for that from the parent strain, and no haemolytic activity could be detected throughout the growth cycle to $18 \mathrm{~h}$ after inoculation. The remaining mutants produced varying low levels of $\mathrm{Ca}^{2+}$-dependent haemolysin activity and were not used further. All eight of the $\mathrm{Hly}^{-}$ mutants were CAMP factor positive and showed a

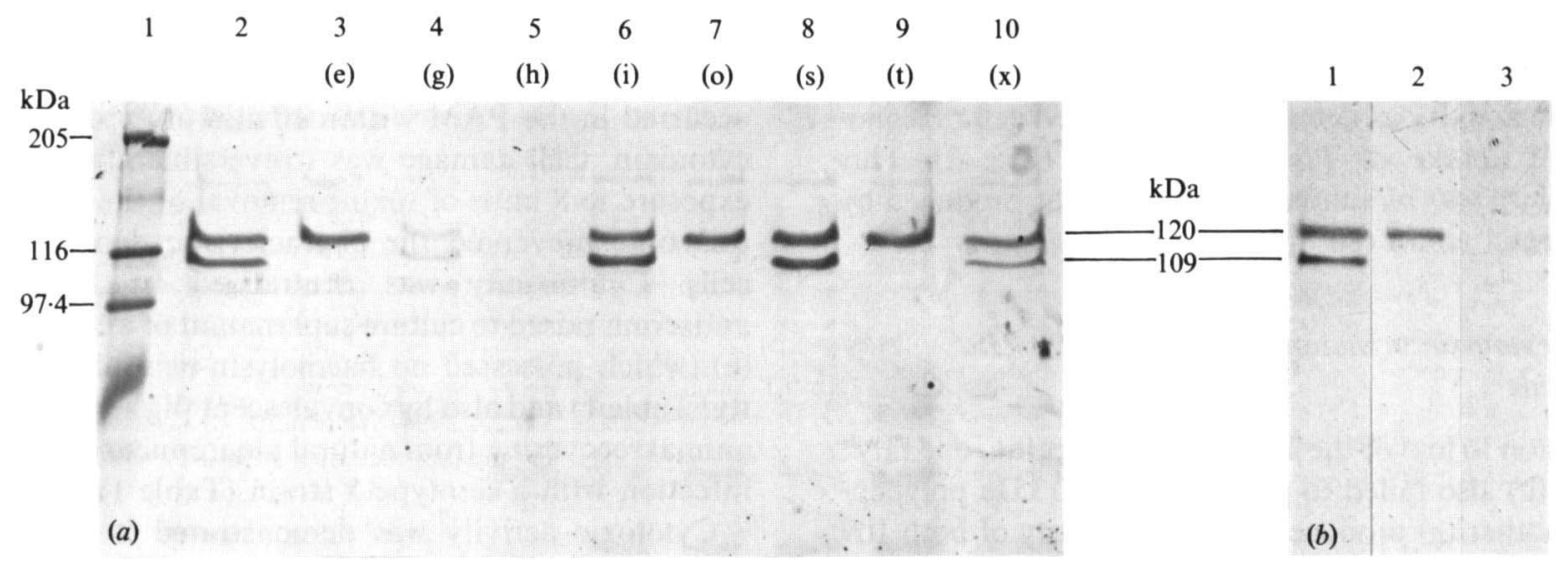

Fig. 1. SDS-PAGE and immunoelectrophoretic blot analysis of cell-free culture fluid of A.pleuropneumoniae HK 361 and its Hlymutants. (a) Coomassie blue staining of extracellular supernatants concentrated 20-fold by ethanol precipitation as described in Methods. Lanes: 1, Molecular mass markers; 2, HK 361; 3-10, Hly- mutants of HK 361. (b) Immunoblot analysis of extracellular supernatants probed with rabbit antibody to culture supernatant of HK 361 . Lanes: 1, HK 361; 2, HK $361 \mathrm{Hly}^{-}$mutant e; 3, HK 361 $\mathrm{Hly}^{-}$, cytotoxin-deficient mutant $\mathrm{h}$. 

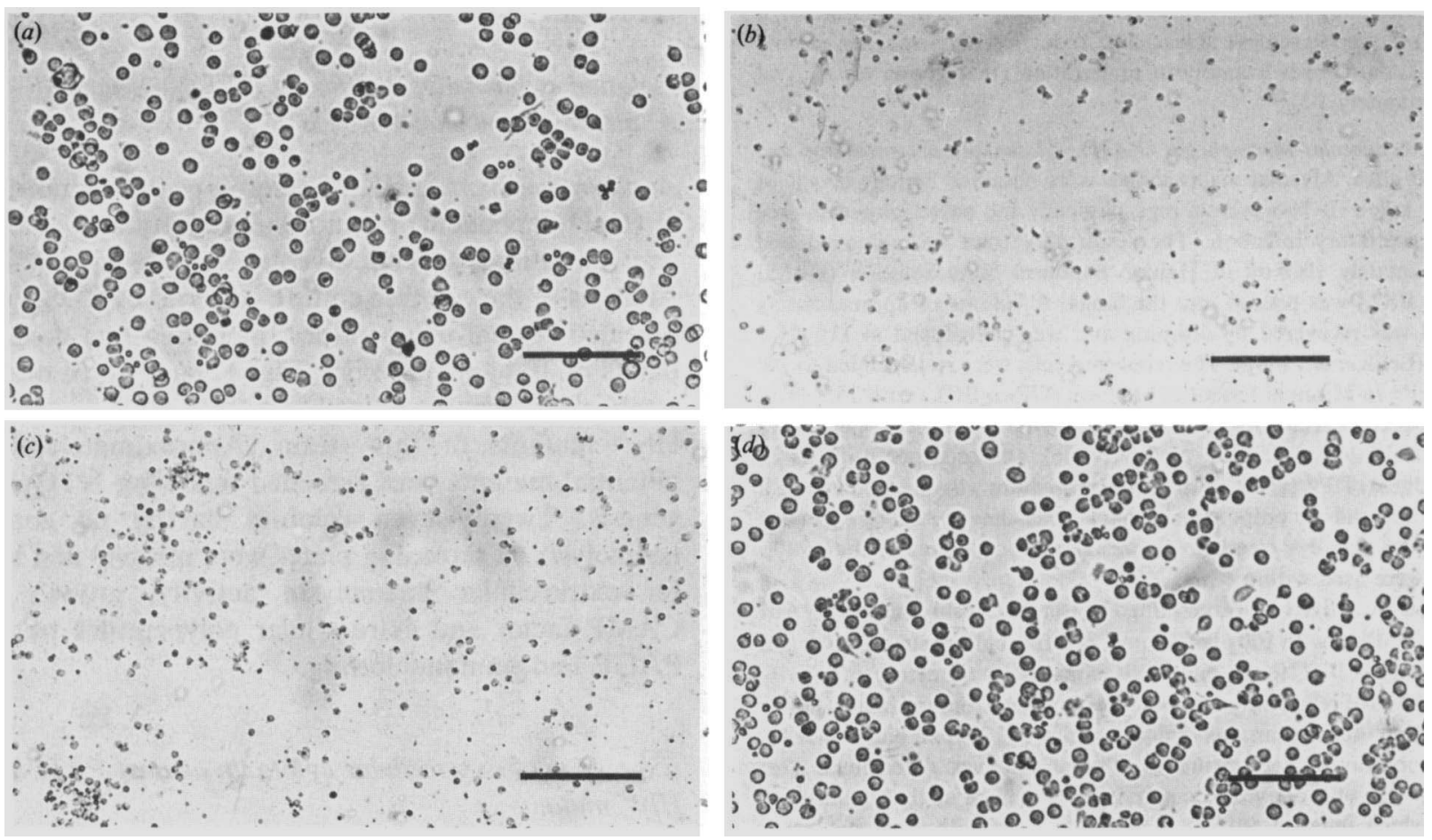

Fig. 2. Effect of cell-free culture supernatants from $A$. pleuropneumoniae HK 361 and mutant strains on fresh porcine alveolar macrophages in culture. Cells were treated with: $(a)$ uninoculated culture fluid, $(b)$ cell-free culture supernatant from $A$. pleuropneumoniae HK 361, (c) cell-free culture supernatant from $A$. pleuropneumoniae HK $361 \mathrm{Hly}^{-}$mutant e, or $(d)$ cell-free culture supernatant from A. pleuropneumoniae HK $361 \mathrm{Hly}^{-}$mutant $\mathrm{h}$. Note PAM in $(b)$ and $(c)$ detached from the culture dish and lysed; remaining cells were lymphocytes and erythrocytes. Bars $0 \cdot 1 \mu \mathrm{m}$.

growth rate indistinguishable from the parent strain. Four of the eight mutants (e, $h$, o and $t)$ produced no $109 \mathrm{kDa}$ extracellular polypeptide band in SDS-PAGE or in immunoblots probed with antibody to cell-free culture supernatant of $A$. pleuropneumoniae HK 361 (Fig. 1). Cell-free culture supernatant from the eight $\mathrm{Hly}^{-}$ mutants was tested for cytotoxicity against fresh PAM. Six of the mutants $(e, i, o, s, t$ and $x)$ showed potent cytotoxic activity as determined by altered cell morphology and uptake of Trypan Blue dye (Fig. 2). This cytotoxicity was of similar potency to that produced by the parental strain (80 units $\mathrm{ml}^{-1}$ ).

\section{Loss of cytotoxin in mutants lacking the $120 \mathrm{kDa}$ polypeptide}

In addition to loss of the $109 \mathrm{kDa}$ polypeptide, one $\mathrm{Hly}^{-}$ mutant $(\mathrm{h})$ also failed to produce the $120 \mathrm{kDa}$ polypeptide. Another $(\mathrm{g})$ produced a small quantity of both 109 and $120 \mathrm{kDa}$ polypeptides (Fig. $1 a$ ). Neither mutant produced any detectable extracellular cytotoxic activity ( $<10$ units $\mathrm{ml}^{-1}$ ). Furthermore, no immunologically cross-reactive $120 \mathrm{kDa}$ band, or cytotoxic activity, could be detected in the cell contents of these mutants.

\section{Characteristics and distribution of A. pleuropneumoniae cytotoxin}

The properties of the cytotoxin were studied in the Hlymutants, where possible interference from haemolytic activity could be excluded. Cytotoxic activity was stable upon heating to $60^{\circ} \mathrm{C}$ for $5 \mathrm{~min}$ but was completely inactivated at $100^{\circ} \mathrm{C}$. Marked morphological changes occurred in the PAM within $10 \mathrm{~min}$ of exposure to the cytotoxin. Cell damage was irreversible after $8 \mathrm{~min}$ of exposure to 8 units of toxin; removal of the toxin up to this time prevented the characteristic damage to the cells. Cytotoxicity was neutralized by homologous antiserum raised to culture supernatant of a $\mathrm{Hly}^{-}$mutant (e) (which possessed no haemolysin-neutralizing activity: Table 1) and also by convalescent pig serum from an animal recovering from natural pleuropneumonia due to infection with a serotype 3 strain (Table 1).

Cytotoxic activity was demonstrated in the culture supernatants of 9 out of $11 \mathrm{~A}$. pleuropneumoniae strains and serotypes tested including representatives of serotypes 2, 3, 4 and 5 (Table 2). Other serotypes were not available for testing. No cytotoxic activity was detected in isolates of A. suis, Haemophilus parasuis, and Pasteur- 


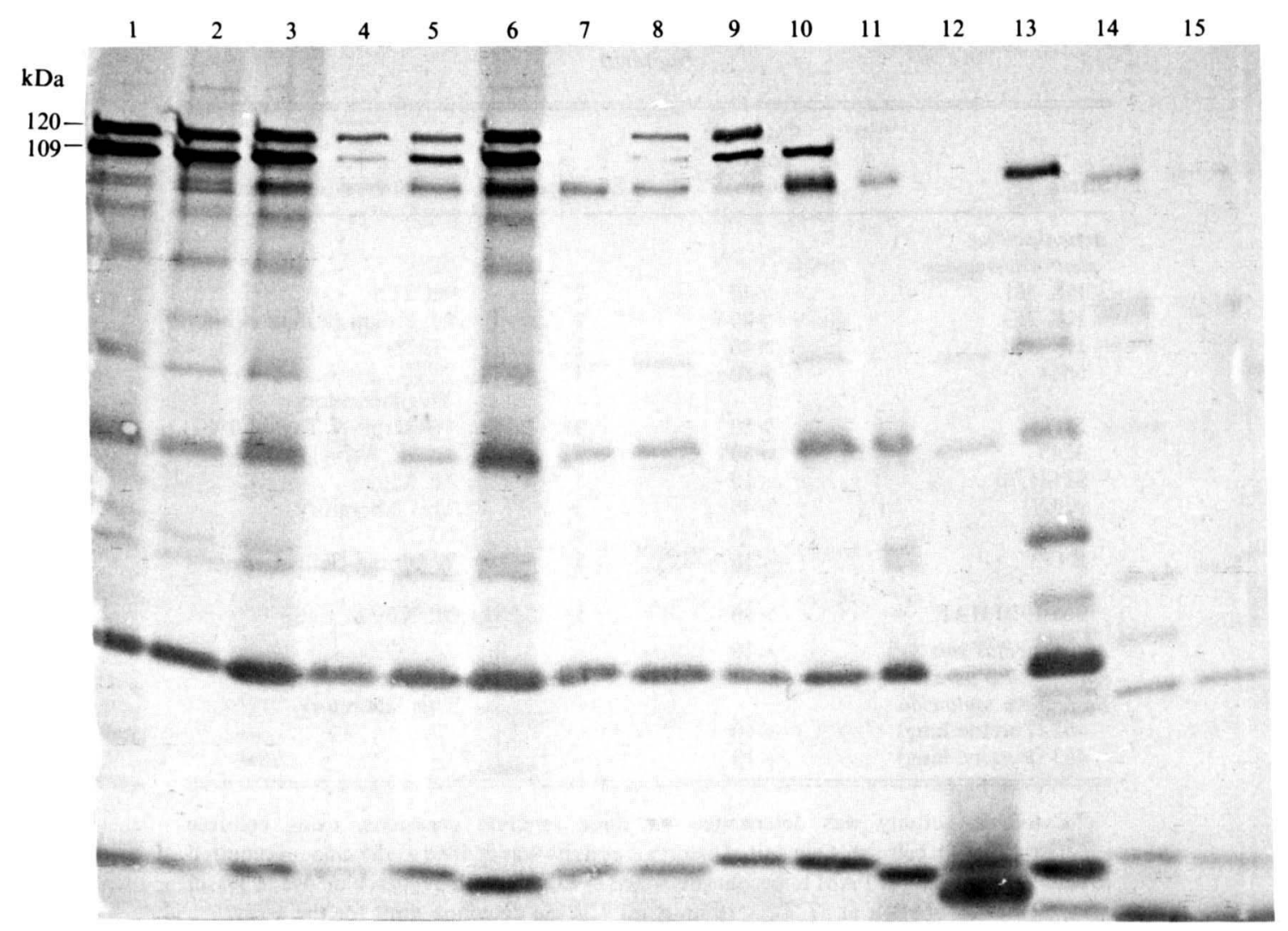

Fig. 3. Comparison of extracellular polypeptides of $A$. pleuropneumoniae isolates representing serotypes 2, 3, 4, and 5, and related porcine bacteria by immunoblot analysis. Cell-free culture fluid was separated by SDS-PAGE, transferred to nitrocellulose membrane and probed with rabbit antibody to culture supernatant of HK 361. Culture fluid from: HK 361 (1); HK 358 (2); HK 353 (3); 6664 (4); DT45 (5); 3245 (6); S1181/70 (7); 9792/3 (8); M62 (9); K17 (10); 266-1920-HAE (11); Haemophilus parasuis (12); A. suis (13); and Pasteurella multocida (14 and 15).

Table 1. Neutralization of haemolytic and cytotoxic activity

\begin{tabular}{|c|c|c|}
\hline Serum & $\begin{array}{l}\text { Anti-haemolytic } \\
\text { activity* }\end{array}$ & $\begin{array}{l}\text { Anti-cytotoxic } \\
\text { activity* }\end{array}$ \\
\hline Rabbit (preimmunization) & $<10$ & $<2$ \\
\hline $\begin{array}{l}\text { Rabbit anti-HK } 361 \text { cell-free } \\
\text { culture supernatant }\end{array}$ & 320 & 64 \\
\hline $\begin{array}{l}\text { Rabbit anti-HK } 361 \text { e cell-free } \\
\text { culture supernatant } \\
\text { Convalescent pig } t\end{array}$ & $\begin{array}{r}<10 \\
80\end{array}$ & $\begin{array}{r}64 \\
128\end{array}$ \\
\hline
\end{tabular}

* Reciprocal dilution of serum required for neutralization as described in Methods.

$\dagger$ Pig serum from animal recovering from natural pleuropneumonia (infection with strain 6664, serotype 3).

ella multocida of porcine origin. Extracellular cytotoxicity was restricted to those strains of $A$. pleuropneumoniae showing a detectable $120 \mathrm{kDa}$ polypeptide by immunoblot analysis (Fig. 3). Cytotoxic activity from all strains tested was neutralized by antibody to $\mathrm{Hly}^{-}$mutant $\mathrm{e}$.
Similarly, it was neutralized by convalescent pig serum from serotype 3 infection (Table 1).

\section{Discussion}

Loss of the $109 \mathrm{kDa}$ polypeptide band in $\mathrm{Hly}^{-}$mutants of $A$. pleuropneumoniae HK 361 indicated that this polypeptide represents the haemolysin molecule or a component of it. The molecular size of this polypeptide agrees approximately with previous estimates of the size of the haemolysin of $A$. pleuropneumoniae serotype 1 as 104 or $105 \mathrm{kDa}$ (Frey \& Nicolet, $1988 a$; Devenish \& Rosendal, 1989). However, our estimation of the size is closer to that made by Fedorka-Cray et al. (1990) and Chang et al. (1989), who reported it to be $110 \mathrm{kDa}$. Hly mutants continued to produce CAMP factor cohaemolysin, confirming the report of Frey et al. (1989) that the latter is not the haemolysin of $A$. pleuropneumoniae.

It has been suggested that the cytotoxic activity of serotype 1 strains of $A$. pleuropneumoniae may be due to 
Table 2. Cytotoxic activity of A. pleuropneumoniae and related porcine bacteria

\begin{tabular}{|c|c|c|c|}
\hline Strain & $\begin{array}{l}\text { Cytotoxic } \\
\text { activity } \\
\text { (units)* }\end{array}$ & Serotype & Source (reference) \\
\hline \multicolumn{4}{|l|}{$\begin{array}{l}\text { Actinobacillus } \\
\text { pleuropneumoniae }\end{array}$} \\
\hline HK 361 & $>40$ & 2 & NCTC $\dagger$ \\
\hline HK 353 & $>80$ & 2 & M. Kilian (Kilian et al., \\
\hline HK 358 & $>40$ & 2 & 1978) \\
\hline 6664 & $>80$ & 3 & \\
\hline DT45 & $>80$ & 3 & $\begin{array}{l}\text { This laboratory } \\
\text { (Rycroft \& Taylor, 1987) }\end{array}$ \\
\hline 3245 & $>80$ & 3 & \\
\hline $\mathrm{S} 1181 / 70$ & $<10$ & 3 & M. Kilian \\
\hline $9792 / 3$ & $>40$ & 3 & This laboratory \\
\hline M62 & $>40$ & 4 & NCTC \\
\hline $\mathrm{K} 17$ & $<10$ & 5 & $\begin{array}{l}\text { T. Inzana (Kilian et al., } \\
\text { 1978) }\end{array}$ \\
\hline 266-1920-HAE & $>10$ & 5 & M. Kilian \\
\hline Actinobacillus suis & $<10$ & - & \\
\hline Haemophilus parasuis & $<10$ & - & \\
\hline Pasteurella multocida & & - & This laboratory \\
\hline 462 (Porcine lung) & $<10$ & - & \\
\hline 463 (Porcine lung) & $<10$ & - & \\
\hline
\end{tabular}

* Cytotoxic activity was determined on three separate occasions, using cell-free supernatant of $4 \mathrm{~h}$ cultures. One unit of cytotoxic activity was defined as the amount required to cause at least $50 \%$ of PAM to become detached or to stain with Trypan blue dye in $1.0 \mathrm{ml}$ after $60 \mathrm{~min}$ incubation at $37^{\circ} \mathrm{C}$. $<10$ units $\mathrm{ml}^{-1}$ is the detection limit for the assay.

$\dagger$ National Collection of Type Cultures, Public Health Laboratory Service, Colindale, London, UK.

the haemolysin, as the activities share characteristics such as heat-lability, and sensitivity to trypsin, oxygen and cholesterol (Rosendal et al., 1988). In these experiments, Hly- mutants of strain HK 361 retained the capacity to secrete a potent cytotoxin active against fresh PAM in vitro. This is the first clear evidence that the secreted cytotoxin is distinct from the haemolysin produced by this organism. The cytotoxic activity showed similar properties to the activity described by Van Leengoed et al. (1989) in being extracellular, heatlabile and active against PAM. Changes in cell morphology at the ultrastructural level were observed after $1 \mathrm{~h}$ exposure by these authors. We found gross morphological changes within $10 \mathrm{~min}$ at dilutions of 1 in 20 or greater, perhaps reflecting quantitative differences in the potency of the prepared toxin rather than any difference in mode of activity.

The finding of two distinct cell-damaging activities in A. pleuropneumoniae does not conflict with the results of others (Rosendal et al., 1988; Kamp \& Van Leengoed, 1989) who found cytotoxic and haemolytic activities to be independently variable in several isolates. It must be concluded that in addition to haemolysin, a second potential virulence determinant is produced by this pathogen. Clearly, if produced in vivo, the rapid action of the toxin is likely to confer properties upon the organism which allow it to overcome the cellular defences in the porcine lung and induce the changes associated with the early stages of the infection (Liggett et al., 1987).

A role for lipopolysaccharide (endotoxin) in the development of lesions in porcine pleuropneumonia has been postulated (Sebunya \& Saunders, 1983; Udeze et al., 1987). In addition, endotoxin is known to cause cytotoxic effects on alveolar macrophages in vitro (Davies \& Barsoum, 1980). Lipopolysaccharide was not involved in the cytotoxic activity reported here since the toxicity was lost in the mutants $\mathrm{g}$ and $\mathrm{h}$. Furthermore, the toxicity was destroyed by heat. This was in general agreement with Udeze et al. (1987), who concluded that a heat-labile factor was involved in lesion development and necrosis.

Our results do not exclude the possibility that type I haemolysin (Frey \& Nicolet, 1988b) or haemolysin from other strains, may itself have cytotoxic activity. However, some strains of $\boldsymbol{A}$. pleuropneumoniae (e.g. K17, serotype 5 and S1181/70, serotype 3) produced haemolysin and secreted the $109 \mathrm{kDa}$ haemolysin polypeptide alone. These were not cytotoxic, indicating that in these 
strains at least, the haemolysin is not cytotoxic. In addition, the cytotoxic activity secreted from $\mathrm{Hly}^{-}$ mutants was identical in potency and effect to that from the parent strain. No additive cytotoxic effect could therefore be attributed to the haemolysin. The relationship of cytotoxin and haemolysin in other serotypes, particularly serotype 1 strains, remains to be resolved, but in view of the very close size and immunological similarity of haemolysins of all the serotypes (Devenish ot al., 1989), it is possible that the cytotoxic activity will prove to be distinct in these organisms also.

Three of the Hly ${ }^{-}$mutants (i, s, and $\mathrm{x}$ ) continued to secrete both 109 and $120 \mathrm{kDa}$ polypeptides. It is likely that these produce a protein with altered structure which is no longer haemolytically active, perhaps due to point mutation. Such a finding is not unexpected. The haemolysin is highly labile (Frey \& Nicolet, 1988a), being rapidly denatured without proteolytic cleavage (unpublished observations).

One $\mathrm{Hly}^{-}$mutant (h) lacked both the $109 \mathrm{kDa}$ and $120 \mathrm{kDa}$ bands while another $(\mathrm{g})$ produced very much reduced amounts of these. Both mutants failed to produce any detectable cytotoxic activity while all those retaining the $120 \mathrm{kDa}$ band were cytotoxic. This indicates that the $120 \mathrm{kDa}$ polypeptide represents the cytotoxin of $A$. pleuropneumoniae. In support of this was the correlation between the presence of a $120 \mathrm{kDa}$ band in extracellular culture supernatant from other strains of A. pleuropneumoniae, and cytotoxic activity. Further evidence for this was the finding that antibody to the culture supernatant from the $\mathrm{Hly}^{-}$mutant e, lacking the $109 \mathrm{kDa}$ polypeptide, neutralized the cytotoxic activity but did not recognize the $109 \mathrm{kDa}$ band, or neutralize the haemolysin. As the cytotoxic activity and its associated $120 \mathrm{kDa}$ polypeptide were functionally and immunologically distinct from the haemolysin, we suggest the term pleurotoxin for this cytotoxic activity.

Mutants of $A$. pleuropneumoniae lacking cytotoxic activity (and the $120 \mathrm{kDa}$ band) were not directly selected, but present among mutants selected for haemolysin deficiency. Mutation of export function could not account for the simultaneous loss of both phenotypes because no intracellular, cross-reactive polypeptide could be detected in those strains by immunoblotting. More likely, it was the result of linkage between the two genes. It is possible that a polar mutation was responsible for the loss of the non-selected phenotype along with the haemolysin protein. Alternatively, inactivation of a regulatory locus such as vir of Bordetella pertussis (Weiss \& Falkow, 1984), could account for this.

We have found the $120 \mathrm{kDa}$ band to be widely distributed among A.pleuropneumoniae. However, it was absent from some strains and from other related bacterial respiratory pathogens of the pig. If this substance were important in the pathogenicity of porcine pleuropneumonia, one would expect it to be present in all isolates of the organism. However, it was noteworthy that the two strains lacking the toxin were originally isolated from non-respiratory sites and were not responsible for pleuropneumonia in the host animals (Kilian $e t$ al., 1978). Surprisingly, the $120 \mathrm{kDa}$ band has not been noted previously as a major extracellular product of $A$. pleuropneumoniae. Devenish et al. (1989) did not detect this polypeptide by immunoblotting with convalescent serum, in the supernatants from any of the 10 serotypes. It is possible that the medium used for haemolysin production (RPMI) was not suitable for pleurotoxin production. We have not examined this possibility.

Little information regarding similar extracellular cytotoxic activity in related Gram-negative bacteria is available. Two high-molecular-mass extracellular polypeptides of similar size $(100$ and $116 \mathrm{kDa})$ were described by Gulig et al. (1984) in Haemophilus influen$z a e$. No activities were ascribed to these but they were considered to be strongly immunogenic, a notable feature of the 109 and $120 \mathrm{kDa}$ proteins of $A$. pleuropneumoniae.

Although the haemolysin has been proposed as a major factor responsible for the lesions of pleuropneumonia, the secretion of a powerful toxin capable of rapidly destroying the primary host defence of the porcine lung must constitute an important facet of the invasive behaviour of this organism.

We acknowledge the assistance of Carole McLay and Allan May, the provision of strains by M. Kilian and T. Inzana, and the advice of D. J. Taylor.

This work was supported by the Wellcome Trust and by Agricultural and Food Research Council grant AG17/201.

\section{References}

Bendixen, P. H., Shewen, P. E., Rosendal, S. \& Wilkie, B. N. (1981) Toxicity of Haemophilus pleuropneumoniae for porcine lung macrophages, peripheral blood monocytes, and testicular cells. Infection and Immunity 33, 673-676.

Bertram, T. A. (1988). Pathobiology of acute pulmonary lesions in swine infected with Haemophilus (Actinobacillus) pleuropneumoniae. Canadian Veterinary Journal 29, 574-577.

Chang, Y.-F., Young, R., Post, D. \& Struck, D. K. (1987). Identification and characterisation of the Pasteurella haemolytica leukotoxin. Infection and Immunity 55, 2348-2354.

Chang, Y.-F., Young, R. \& Struck, D. K. (1989). Cloning and characterization of a hemolysin gene from Actinobacillus (Haemophilus) pleuropneumoniae. DNA 8, 635-647.

DAVIS, B. \& BARSOUM, I. (1980). Human alveolar macrophages: effect of endotoxin in vitro. Infection and Immunity 30, 753-758.

DEVENISH, J. \& RosendaL, S. (1989). Identification of the heat-labile hemolysin of Actinobacillus pleuropneumoniae serotype 1. Canadian Journal of Veterinary Research 53, 251-254.

Devenish, J., Rosendal, S., Johnson, R. \& Hubler, S. (1989). Immunoserological comparison of 104-kilodalton proteins associated with hemolysis and cytolysis in Actinobacillus pleuropneumoniae, 
Actinobacillus suis, Pasteurella haemolytica, and Escherichia coli. Infection and Immunity 57, 3210-3213.

Fedorka-Cray, P. J., Huether, M. J., Stine, D. L. \& Anderson, G. A. (1990). Efficacy of a cell extract from Actinobacillus (Haemophilus) pleuropneumoniae serotype 1 against disease in swine. Infection and Immunity 58, 358-365.

Frey, J. \& Nicolet, J. (1988a). Purification and partial characterisation of a hemolysin produced by Actinobacillus pleuropneumoniae type strain 4074. FEMS Microbiology Letters 55, 41-46.

FREY, J. \& NICOLET, J. (1988b). Regulation of hemolysin expression in Actinobacillus pleuropneumoniae serotype 1 by $\mathrm{Ca}^{2+}$. Infection and Immunity 56, 2570-2575.

FreY, J., Perrin, J. \& Nicolet, J. (1989). Cloning and expression of a cohemolysin, the CAMP factor of Actinobacillus pleuropneumoniae. Infection and Immunity 57, 2050-2056.

Gulig, P. A., Frisch, C. F. \& Hansen, E. J. (1983). A set of two monoclonal antibodies specific for the cell surface-exposed $39 \mathrm{~K}$ major outer membrane protein of Haemophilus influenzae type b defines all strains of this pathogen. Infection and Immunity 42, 516524.

Gulig, P. A., McCracken, G. H., Holmans, P. L. \& Hansen, E. J. (1984). Immunogenic proteins in cell-free culture supernatants of Haemophilus influenzae type b. Infection and Immunity 44, 41-48.

Gygi, D., Nicolet, J., Frey, J., Cross, M., Koronakis, V. \& Hughes, C. (1990). Isolation of the Actinobacillus pleuropneumoniae haemolysin gene and the activation and secretion of the prohaemolysin by the HlyC, HlyB and HlyD proteins of Escherichia coli. Molecular Microbiology 4, 123-128.

HaRlow, E. \& LANE, D. (1988). Antibodies : a Laboratory Manual. Cold Spring Harbor, NY : Cold Spring Harbor Laboratory.

KAMP, E. M. \& VAN LeEngoed, L. A. M. G. (1989). Serotype-related differences in production and type of heat-labile hemolysin and heatlabile cytotoxin of Actinobacillus (Haemophilus) pleuropneumoniae. Journal of Clinical Microbiology 27, 1187-1191.

Kilian, M., Nicolet, J. \& Biberstein, E. L. (1978). Biochemical and serological characterization of Haemophilus pleuropneumoniae (Matthews and Pattison 1961) Shope 1964 and proposal of a neotype strain. International Journal of Systematic Bacteriology 28, 2026.

Kume, K., NAKaI, T. \& SaWATA, A. (1986). Interaction between heatstable hemolytic substance from Haemophilus pleuropneumoniae and porcine pulmonary macrophages in vitro. Infection and Immunity 51, 563-570.

LeiJh, P. C. J., VAN FurTh, R. \& VAN Zwet, T. L. (1986). In vitro determination of phagocytosis and intracellular killing by polymorphonuclear and mononuclear phagocytes. In Handbook of Experimental Immunology, vol. 2, Cellular Immunology. 4th edn, pp. 46.146.21. Edited by D. M. Weir. Oxford: Blackwell Scientific Publications.

Liggett, A. D., Harrison, L. R. \& Farrell, R. L. (1987). Sequential study of lesion development in experimental haemophilus pleuropneumonia. Research in Veterinary Science 42, 204-221.
Ludwig, A., JARChaU, T., Benz, R. \& Goebel, W. (1988). The repeat domain of $E$. coli hemolysin (HlyA) is responsible for its $\mathrm{Ca}^{2+}$ dependent binding to erythrocytes. Molecular and General Genetics 214, 553-561.

Martin, P. G., Lachance, P. \& Niven, D. F. (1985). Production of RNA-dependent haemolysin by Haemophilus pleuropneumoniae. Canadian Journal of Microbiology 31, 456-462.

Miller, J. H. (1972). Experiments in Molecular Genetics. Cold Spring Harbor, NY: Cold Spring Harbor Laboratory.

Nicolet, J. (1986). Haemophilus infections. In Diseases of Swine, pp. 426-436. Edited by A. D. Leman, B. Straw, R. D. Glock, W. L. Mengeling, R. H. C. Penny \& E. Scholl. Ames: Iowa State University Press.

NiCOLET, J. (1990). Overview of the virulence attributes of the HAPgroup of bacteria. Canadian Journal of Veterinary Research (Supplement) 54, S12-S15.

RENNIE, R. P., FreER, J. H. \& ARBUthnotT, J. P. (1974). The kinetics of erythrocyte lysis by Escherichia coli haemolysin. Journal of Medical Microbiology 7, 189-195.

Rosendal, S., Mitchell, W. R., Weber, M., Wilson, M. R. \& ZAMAN, M. R. (1980). Haemophilus pleuropneumonia. Lung lesions induced by sonicated bacteria and sterile culture supernatant. Proceedings of the International Pig Veterinary Society Congress 6, 221.

Rosendal, S., Devenish, J., Macinnes, J. I., Lumsden, J. H., WATSON, S. \& XUN, H. (1988). Evaluation of heat-sensitive, neutrophil-toxic, and hemolytic activity of Haemophilus (Actinobacillus) pleuropneumoniae. American Journal of Veterinary Research 49, 1053-1058.

RyCroft, A. N. \& TAYLoR D. J. (1987). Preparation and characterisation of envelope proteins from Haemophilus pleuropneumoniae. Veterinary Microbiology 15, 303-314.

Sebunya, T. N. K. \& SAUnders, J. R. (1983). Haemophilus pleuropneumoniae infection in swine: a review. Journal of the American Veterinary Medical Association 182, 1331-1337.

ShOPE, R. E. (1964). Porcine contagious pleuropneumonia. I. Experimental transmission, etiology and pathology. Journal of Experimental Medicine 119, 357-368.

StrathdeE, C. A. \& Lo, R. Y. C. (1987). Extensive homology between the leukotoxin of Pasteurella haemolytica and the $\alpha$-hemolysin of Escherichia coli. Infection and Immunity 55, 3233-3236.

UDEZE, F. A. \& KADIS, S. (1988). Effect of Actinobacillus pleuropneumoniae hemolysin on viability and function of porcine phagocytes. Proceedings of the International Pig Veterinary Society Congress 10, 64.

UDEZE, F. A., LATIMER, K. S. \& KADIS, S. (1987). Role of Haemophilus pleuropneumoniae lipopolysaccharide endotoxin in the pathogenesis of porcine Haemophilus pleuropneumonia. American Journal of Veterinary Research 48, 768-773.

VAN Leengoed, L. A., KAMP, E. M. \& Pol, J. M. A. (1989). Toxicity of Haemophilus pleuropneumoniae to porcine lung macrophages. Veterinary Microbiology 19, 337-349.

WEISS, A. A. \& FALKOW, S. (1984). Genetic analysis of phase change in Bordetella pertussis. Infection and Immunity 43, 263-269. 